\title{
Constipação na Gravidez
}

\section{Constipation in Pregnancy}

\author{
FABIO SHIGUEHISSAKAWAGUTI'; WILMARARTUR KLUG ${ }^{2}$; CHIA BIN FANG $^{3}$; \\ JORGEALBERTO ORTIZ $;$ PERETZCAPELHUCNICK ${ }^{5}$
}

${ }^{1}$ Residente do Departamento de Cirurgia; ${ }^{2}$ Professor Titular, Chefe de Clínica; ${ }^{3}$ Professor Adjunto;
${ }^{4}$ Mestre em cirurgia; ${ }^{5}$ Professor Titular da Faculdade de Ciências Médicas - São Paulo - SP.

KAWAGUTI FS; KLUG WA; FANG CB; ORTIZ JA; CAPELHUCNICK P. Constipação na Gravidez. Rev bras Coloproct, 2008;28(1): 046-049.

RESUMO: Introdução: Constipação na gravidez é sintoma comum, mas para seu diagnóstico são necessários dois ou mais sintomas persistentes, como ritmo intestinal mais lento, dificuldade para evacuar, fezes endurecidas ou sensação de evacuação incompleta. Existem múltiplos fatores envolvidos, hormonais, sedentarismo, ingestão de fibras ou líquidos, uso de medicamentos, etc. Objetivo do estudo: analisar a incidência de constipação em 41 gestantes sadias do Ambulatório de Obstetrícia da Santa Casa de São Paulo. Método: a pesquisa se fez através do preenchimento de um questionário sobre ritmo intestinal, hábitos de vida, sintomas digestivos antes e após a gravidez. Resultados: observamos que constipação incidiu em $27,6 \%$ daquelas que não sofriam sintomas pregressos. Conclusão: a incidência de constipação na gestação é menor que o usualmente estimado, começa no início da gravidez, e devido ao baixo índice encontrado não há razão para uso indiscriminado de laxativos.

Descritores: Constipação, gravidez, motilidade, motilina.

\section{INTRODUÇÃO}

A constipação é um problema digestivo muito comum, sendo bastante freqüente no período gestacional. Para melhor caracterização, foram estabelecidos critérios que facilitam o diagnóstico, que incluem: ritmo intestinal com menos de três evacuações por semana, sensação de dificuldade para evacuar, fezes pequenas e endurecidas e sensação de evacuação incompleta. Considera-se constipado o paciente que apresentar dois ou mais desses sintomas por período mínimo de três meses ao longo do ano. As manifestações clínicas das alterações funcionais do tubo digestivo são freqüentes na gestação, mas poucos trabalhos avançam além da notificação dos sintomas e de quando eles ocorrem. Entre estas alterações citam-se diminuição da pressão da cárdia ${ }^{1}$, estase biliar ${ }^{2}$, e diminuição da velocidade do trânsito do intestino delgado ${ }^{3}$. Em linhas gerais ocorre motilidade reduzida do cólon, tempo de trânsito prolongado, propiciando aumento de absorção de água. As fezes tornam-se menos volumosas, por menor concentração de água, contribuindo para a constipação ${ }^{4}$. A explicação para estes eventos relaciona-se com a diminuição da concentração plasmática de motilina, por influência da progesterona na gravidez, um polipeptídio intestinal que estimula a contração das fibras lisas do intestino ${ }^{5}$. Parece haver também um papel para a somatostatina na regulação do motilidade na gestação ${ }^{6}$. Outros fatores devem ser considerados na gênese ou agravamento dos sintomas. Entre eles inclui-se o programa alimentar, nível de atividade física, ingestão de água ${ }^{7}$, e quantidade adequada de fibras ${ }^{8}$, embora algumas gestantes com constipação grave possam piorar os sintomas ingerindo fibras em excesso ${ }^{9}$.

$\overline{\text { Trabalho realiza }} d o$ na Disciplina de Coloproctologia do Departamento de Cirurgia e Dep. de Ginecologia e Obstetrícia - Santa Casa de São Paulo - Faculdade de Ciências Médicas - São Paulo - SP - Brasil. 
Além disso, em vista do prolongamento do tempo de trânsito há maior absorção de água e isso resseca as fezes.

Por serem frequientes, as queixas de constipação na gestação levam obstetras a prescrever laxativos rotineiramente. Porém, como estão já estabelecidos critérios para conceituar constipação, estas prescrições deveriam ser feitas menos vezes.

\section{OBJETIVO}

O objetivo do estudo foi avaliar a incidência da constipação em gestantes em nosso meio, e verificar a existência de outros fatores que possam interferir provocando alterações no trânsito intestinal.

\section{CASUÍSTICA E MÉTODO}

Após aprovação pelo CEP da Santa Casa de São Paulo, foram entrevistadas 41 gestantes ao final da gravidez no Ambulatório de Baixo Risco do Departamento de Obstetrícia e Ginecologia da Santa Casa de São Paulo. Foram incluídas maiores de idade que consentissem participar da entrevista, e estivessem classificadas como sãs, e não necessitassem medicar-se de forma a interferir nos resultados, além de terem autorizado a obtenção de dados clínicos.

As pacientes responderam a um questionário que considerava:

a) ritmo intestinal antes e durante a gestação;

b) Sintomas antes e durante a gestação; estes incluíam dificuldade para evacuar, sensação de evacuação incompleta, fezes pequenas e duras, necessidade de usar laxativos ou outros, como eructação, náuseas, vômitos, regurgitação, distensão, sensação de empachamento, anorexia, cólicas, flatulência.

c) hábitos de vida, incluindo dieta e atividade física antes da gestação; estes incluíam quantificação da ingestão de verduras, frutas, líquidos e intensidade de atividade ou sedentarismo.

d) mudanças durante a gestação;

e) aspectos psicológicos, incluindo referência a depressão, ansiedade, estresse ou outros.

\section{RESULTADOS}

Após análise dos dados obtidos no item ritmo intestinal, foram separados três grupos: as 10 que apresentaram retardo do trânsito, as 21 que o mantiveram constante e as 10 restantes que o aceleraram. (Tabela 1).

Das dez pacientes que perceberam diminuição do ritmo intestinal, oito manifestaram a alteração precocemente, já no primeiro trimestre, uma no segundo e a última já ao final da gestação. Foram classificadas como constipadas pelo critério definido anteriormente apenas oito, sendo os principais sintomas relatados dificuldade para evacuar e fezes pequenas e duras. Das pacientes cujo trânsito intestinal persistiu inalterado durante a gestação, apenas três $(14,3 \%)$ referiram outros sintomas digestivos relacionados com constipação. Naquelas que aceleraram o trânsito, apenas duas (20\%) das dez pacientes referiram algum sintoma correlato. Do total, $12(29,3 \%)$ das pacientes que referiram sintomas relacionados com constipação, já os apresentavam antes da gestação. Quanto às questões relacionadas com Hábitos de Vida, 20 afirmaram que houve melhora com a gestação, seja no que se refere aos modos de alimentação ou correção do sedentarismo. Doze não apresentaram nenhuma alteração, e nove consideraram haver piorado seus hábitos de alimentação ou atividade física, a despeito de prosseguirem com as consultas de pré-natal e terem sido orientadas por médicos.(Tabela 2). As raras referências aos aspectos psicológicos não foram relacionáveis com as alterações da função intestinal.

\section{DISCUSSÃO}

A análise dos resultados mostrou que a incidência de constipação na gestação de pacientes nor-

Tabela 1 - Ritmo intestinal de 41 gestantes, comparado com o anterior à gravidez.

\begin{tabular}{lll}
\hline Retardo do ritmo das evacuações & 10 & $24,4 \%$ \\
Trânsito intestinal inalterado & 21 & $51,2 \%$ \\
Trânsito acelerado & 10 & $24,4 \%$ \\
\hline
\end{tabular}

Tabela 2 - Alterações nos hábitos de vida (alimentação e atividade física) na gestação.

\begin{tabular}{lrr}
\hline Melhora dos hábitos & 20 & $48,8 \%$ \\
Hábitos inalterados & 12 & $29,3 \%$ \\
Hábitos piorados & 9 & $21,9 \%$ \\
\hline
\end{tabular}


mais não atinge números tão elevados quanto é geralmente suposto. Tal se deve, em princípio, a que o conceito exige definição precisa de alguns sintomas específicos e duração persistente deles. Ora, a conduta geralmente tomada de prescrever aleatoriamente os laxativos, cria a falsa sensação da sua necessidade. Existem mitos como o de ser necessário evacuar diariamente para evitar conseqüências "tóxicas", que poderiam envenenar a futura mãe e seu feto se não forem prontamente eliminadas ${ }^{9}$. Outra suposição é a de que se as evacuações não forem bem amolecidas, as grávidas não conseguirão exonerá-las, "limpando" os intestinos para prevenir possíveis outros sintomas desagradáveis. O uso indiscriminado de laxativos, ainda alimenta a falsa expectativa que haveria um suposto "efeito rebote"caso a medicação seja interrompida.

Do ponto de vista quantitativo, observamos que do total de $24 \%$ que referiram lentidão do trânsito intestinal, apenas $19,5 \%$ seriam efetivamente consideradas constipadas pelos critérios geralmente aceitos. Eliminando do cálculo aquelas que já apresentavam constipação prévia à gravidez, poderíamos considerar que durante a gestação $34,5 \%$ apresentaram lentidão do trânsito, e 27,6\% enquadraram-se no conceito diagnós- tico de constipação. Estes dados concordam com os citados em outras publicações ${ }^{7,10}$, sendo evidentemente variáveis conforme o tipo de controle e orientação médica prestados. Por outro lado, em avaliação das atitudes tomadas pelas gestantes, há na maioria o desejo consciente de melhorar seus hábitos de vida, o que pode evidentemente minimizar o efeito das alterações gestacionais, bem como as orientações de prénatal. A instalação da mudança do ritmo intestinal é geralmente precoce, no primeiro trimestre. Isso contraria a hipótese formulada das alterações nas taxas plasmáticas de progesterona, que aumentam no decurso da gravidez, via inibição da motilina, serem o fator biológico fundamental.

\section{CONCLUSÕES}

A gestação é seguida de constipação em aproximadamente uma em cada quatro grávidas. Na maior parte o quadro se instala já no início, no primeiro trimestre. Não encontramos suporte, com base nos resultados, para a orientação geral de prescrever laxativos de maneira indiscriminada, sendo mais importante boa orientação médica geral.

\begin{abstract}
Background: constipation is a common problem during pregnancy, but for a definitive diagnosis, symptoms such as low motility, defecation difficulties, hard feces and incompletet evacuation should be evaluated. There are a number of factors involved, including hormones, physical activity, water and fiber intake, medication, etc. Objective: the objective of the present study was to analyse the occurence of constipation in 41 normal pregnant women from the Ambulatory of Obstetrics and Gynecology Department at Santa Casa Hospital in São Paulo. Method: the patients filled a questionnaire with questions related to the frequency of stools, personal habits, symptoms and any other related conditions, before and after pregnancy. Results: the overall incidence of constipation was $27.6 \%$, excluding the subjects with previous history. Conclusion: we concluded that the incidence of constipation is lower than expected and generally occurs since the beginning of pregnancy. There seems to be no reason for the prescription of laxatives in most cases in pregnancy.
\end{abstract}

Key words: Constipation, pregnancy, motility, motilin.

\section{REFERÊNCIAS}

1. Nagler R; Spiro HM. Heartburn in late pregnancy. Manometric studies of esophageal motor function. J Clin Invest, 1961; 40: 954-960.

2. Ylostato P; Kirkinen P; Heikkinen J; Maentausta O. Gallbladder volume and serum bile acids in cholestasis of pregnancy. Br J Obstet Gynaecol, 1982; 89: 59-61.

3. Lawson M; Kern Jr ;F Everson GT. Gastrointestinal transit time in human pregnancy: prolongation in the second and third trimesters followed by postpartum normalization. Gastroenterology, 1985; 89: 996-999.
4. Blackburn ST; Loper DL. The gastrointestinal and hepatic systems and perinatal nutrition. In: Maternal, fetal and neonatal physiology-a clinical perspective. 1992; pg 384385; Philadelphia, Saunders \& Co.

5. Qiu XH; Yang MG; Pengg JJ; Huang YX; Xu CF et al. Changes of plasma motilin concentration in pregnancy and early postpartum period. Sheng Li Xue Bao, 1994; 46(1): 100-104.

6. Holst N; Jenssen TG; Burhol PG. Plasma concentrations of motilin and somatostatin are increased in late pregnancy and postpartum. Br J Obstet Gynaecol, 1992; 99(4): 338341. 
Vol. 28
7. Derbyshire E; Davies J; Costarelli V; Dettmar P. Diet, physical inactivity and the prevalence of constipation throughout and after pregnancy. Matern Chil Nutr, 2006; 2(3): 127-134.

8. Jewell DJ; Young G. Interventions for treating constipation in pregnancy. Cochrane Database Syst Rev, 2001; (2): CD 001142.

9. Müller-Lissner SA; Kamm MA; Scarpignato C; Wald A. Myths and misconceptions about chronic constipation. Am J Gastroenterol, 2005; 100(1): 232-242.
10. Klug WA; Aguida, HAC; Ortiz JA; Fang CB; Capelhuchnik P. Alterações das pressões anais na gravidez. Rev bras Coloproct, 2007; 27(2): 196-201.

Endereço para correspondência:

WILMAR ARTUR KLUG

Alameda Ribeirão Preto, 487 - Ap. 103

Cep 01331-001 - São Paulo - SP

E-mail: klug@doctor.com 